\title{
PENGARUH KEBIASAAN BELAJAR DAN SELF-EFFICACY TERHADAP HASIL BELAJAR GEOGRAFI DI SMA
}

\author{
Fatiya Rosyida ${ }^{1}$, Sugeng Utaya ${ }^{2}$, Budijanto ${ }^{3}$ \\ Email: fatiya.rosyida.fis@um.ac.id, sugeng.utaya.fis@um.ac.id, \\ budijanto.fis@um.ac.id
}

\begin{abstract}
Abstrak: Tujuan penelitian ini untuk mengetahui adanya (1) pengaruh kebiasaan belajar terhadap hasil belajar Geografi, (2) pengaruh self-efficacy terhadap hasil belajar Geografi, dan (3) pengaruh kebiasaan belajar dan self-efficacy terhadap hasil belajar Geografi di SMAN 1 Widang-Tuban. Data dikumpulkan dengan menyebarkan angket dan dokumentasi dari 94 responden. Kebiasaan belajar diukur dengan angket kebiasaan belajar yang dikembangkan oleh Bakare 1971. Instrumen Motivation and Strategi Learning Quetionare (MSLQ) yang dikembangkan oleh Pintrich dkk tahun 1991 digunakan untuk mengukur self-efficacy, sedangkan hasil belajar siswa diperoleh dari nilai rata-rata ulangan. Setelah data terkumpul, dianalisis secara statistik dengan teknik regresi. Hasil penelitian menunjukkan bahwa (1) kebiasaan belajar secara signifikan berpengaruh terhadap hasil belajar siswa dengan sumbangan efektif sebesar 65,60\%, (2) Selfefficacy secara signifikan berpengaruh terhadap hasil belajar siswa dengan sumbangan efektif sebesar 15,80\%, dan (3) kebiasaan belajar dan self-efficacy secara signifikan berpengaruh terhadap hasil belajar siswa dengan sumbangan efektif sebesar 65,20.
\end{abstract}

Kata Kunci: kebiasaan belajar, self-efficacy, hasil belajar.

\section{PENDAHULUAN}

Keberhasilan atau kegagalan siswa dalam belajar dapat dilihat dari hasil belajarnya. Jika siswa memperoleh hasil belajar baik maka dapat dikatakan siswa tersebut berhasil. Begitu pula sebaliknya, siswa yang memiliki hasil belajar rendah dapat dikatakan gagal. Selain sebagai tolak ukur keberhasilan siswa dalam belajar, hasil belajar juga menjadi acuan keberhasilan guru dalam melakukan pembelajaran. Pembelajaran dikategorikan baik atau berhasil apabila tujuan pembelajaran dapat tercapai. Ketercapaian tujuan pembelajaran tersebut dapat dilihat dari hasil belajar yang baik.
Hasil belajar menjadi penting bagi guru dan siswa karena menjadi acuan keberhasilannya dalam pembelajaran. Selain itu, hasil belajar juga menjadi acuan penilaian kualitas sekolah seperti diungkapkan oleh Mendezebal (2013).

Student's academic performance occupies a very important place in education as well as in the learning process. It is considered as a key criterion to judge one's total potentialities and capacities which are frequently measured by the examination results. It is used to pass judgment on the quality of educa- 
90

Fatiya Rosyida, Sugeng Utaya, Budijanto. Pengaruh Kebiasaan Belajar dan Self-Efficacy

Terhadap Hasil Belajar Geografi Di SMA

tion offered by academic institutions.

Tentunya, hasil yang diharapkan adalah hasil belajar optimal dan tinggi karena setiap orang menginginkan pres-tasi yang tinggi. Namun, antara siswa satu dengan lainnya berbeda dalam pencapaian hasil belajar. Ada siswa yang mampu mencapai prestasi tinggi, tetapi ada pula yang prestasi belajarnya rendah.

Bervariasinya hasil belajar yang diperoleh siswa di sekolah ditentukan oleh berbagai faktor yang mempenga-ruhinya. Secara umum faktor-faktor yang mempengaruhi hasil belajar dapat digolongkan dalam dua faktor, yaitu internal dan eksternal. Menurut Dimyati dan Mudjiono (2010) faktor internal yang terbentuk dari dalam diri siswa itu sendiri antara lain kesehatan jasmani rohani, sikap, intelegensi dan bakat, minat, motivasi, kebiasaan belajar, dan lain sebagainya, sedangkan faktor eksternal yang berasal dari luar diri siswa itu antara lain lingkungan keluarga, lingkungan sekolah, guru, masyarakat serta ling-kungan sekitar. Lebih lanjut, Suwardi (2012) menjelaskan mengenai kontribusi masing-masing faktor tersebut terhadap hasil belajar. Ia menemukan faktor yang berpengaruh terhadap hasil belajar, yaitu (1) Faktor psikologi siswa $(27,54 \%)$, (2) Faktor lingkungan masyarakat $(10,18 \%)$, (3) Faktor lingkungan sekolah $(8,70 \%)$, (4) Faktor pendukung belajar $(6,98 \%),(5)$ Faktor lingkungan keluarga $(6,50 \%)$, dan (6) Faktor waktu sekolah $(6,23 \%)$.

Berdasarkan penelitian Suwardi (2012) tersebut, faktor terbesar yang mempengaruhi hasil belajar adalah faktor psikologi sebesar 27,54\%. Oleh karena itu, dapat disimpulkan bahwa faktor psikologis memberikan kontribusi yang besar dalam keberhasilan belajar siswa. Self-efficacy dan kebiasaan belajar merupakan faktor psikologi sehingga faktor tersebut juga berpengaruh dalam menentukan hasil belajar. Self-efficacy berperan sebagai pendorong, sedangkan kebiasaan belajar sebagai strategi agar memperoleh hasil belajar yang baik.

Kebiasaan belajar merupakan faktor penting dalam proses belajar. Hal tersebut sesuai dengan pendapat Rana dan Kausar (2011). Mereka menyatakan bahwa kunci utama dari keberhasilan belajar siswa adalah kebiasaan belajar baik. Kebiasaan belajar baik akan membuat siswa memperoleh prestasi belajar tinggi. "Students with better strategies and better study habits tend to show higher academic achievement" (Aluja dan Blanch, 2004). Hal tersebut dapat terjadi karena kebiasaan belajar baik akan mampu menciptakan suasana belajar yang benar-benar mendukung untuk belajar. "Suasana belajar baik merupakan suasana yang tepat dalam memahami apa yang sedang dipelajari oleh siswa tersebut, dengan begitu penguasaan terhadap suatu materi pelajaran akan semakin meningkat" (Wahyuningsih dan Djazari, 2013).

Selain itu, kebiasaan belajar baik akan membawa pengaruh positif bagi siswa, seperti pembuatan jadwal belajar yang dilaksanakan dan dipertanggungjawabkan sendiri. Dengan adanya jadwal belajar siswa bisa membagi waktu belajarnya, kapan harus mengulang pelajaran agar tidak mudah lupa dan kapan mempersiapkan diri untuk sekolah esok harinya. Dengan terbiasa belajar setiap hari, siswa dapat mengulangi bahan pelajaran yang telah diberikan oleh guru pada 
hari itu juga. Pengulangan yang dilakukan siswa terus-menerus membuat mereka lebih memahami pelajaran bahkan untuk materi sulit sekalipun. Slameto (2003) berpendapat bahwa "siswa menjadi makin baik penguasaan-nya jika kepada mereka diberikan banyak kesempatan untuk mengulang".

Penguasaan materi pelajaran baik akan meningkatkan hasil belajar siswa. Hasil belajar yang baik tersebut bukan hanya pada satu mata pelajaran saja, tetapi juga keseluruhan mata pelajaran. Siswa dengan kebiasaan belajar baik akan tekun dan rajin belajar sehingga kesuk-sesan belajar akan dicapai di semua mata pelajaran yang ditempuhnya. "Students who have proper study habits and attitudes are also successful academically are evident according to many studies" (Ozsoy dkk., 2009). Jadi siswa yang memiliki kebiasaan belajar baik cende-rung dapat hidup dengan penuh disiplin dan bertanggung jawab dalam setiap tindakan belajarnya untuk mencapai prestasi belajar yang tinggi.

Pentingnya kebiasaan belajar untuk meningkatkan hasil belajar dibuktikan oleh ahli dengan melakukan penelitian tentang pengaruh kebiasaan belajar terhadap hasil belajar. Hasil penelitian tersebut mengungkapkan bahwa kebia-saan belajar berpengaruh signifikan terhadap hasil belajar (Oyedeji, 1991; Khurshid, dkk, 2012; Wiyono, 2003; dan Rahyuningsih dkk, 2012).

Kebiasaan belajar saja tidak cukup untuk membuat hasil belajar menjadi baik. Faktor lain yang memengaruhi hasil belajar adalah self-efficacy. Self-efficacy adalah keyakinan seseorang terhadap kemampuan mereka agar bisa berhasil mencapai tujuan. (Bandura, 1994; Pajares, 2005; Schunk dan Meece, 2005; dan Zimmerman 2000). Keyakinan tersebut mendorong siswa untuk mencapai keberhasilan. Karena dengan keyakinan tinggi mereka akan berupaya sekuat tenaga untuk mencapai tujuan yaitu prestasi belajar.

Self-efficacy dapat meningkatkan keberhasilan siswa melalui dua cara yakni, pertama, keyakinan diri akan menumbuhkan minat dalam diri terhadap kegiatan yang dianggapnya menarik. Kedua, mereka akan mengatur diri untuk meraih tujuan dan berkomitmen kuat (Bandura, 1994). Siswa dengan self-efficacy tinggi akan menyakini bahwa tugas sebagai tantangan bukan ancaman, sehingga mereka akan meminimalkan gangguan, menerapkan strategi efektif, menemukan mitra belajar, tidak mudah putus asa bahkan bisa mengatasi kegagalan yang dihadapi (Schunk dan Meece 2005). Berbeda dengan siswa dengan self-efficacy rendah, mereka berkeyakinan bahwa tidak akan mampu melaksanakan tugas bahkan sebelum tugas itu diberikan (Pajares, 2005). Akibatnya, mereka akan melaksanakan pembelajaran dengan keraguan dan ketakutan. Mereka juga akan mudah mengalami depresi dan stres sehingga dapat mempertimbangkan untuk tidak mengikuti pembelajaran. (Bandura 1994).

Pentingnnya self-efficacy untuk meningkatkan hasil belajar dibuktikan dengan melakukan penelitian tentang pengaruh self-efficacy terhadap hasil belajar. Hasil Penelitian menunjukkan bahwa efikasi diri berpengaruh signifikan terhadap hasil belajar. (Mothlag, dkk. 2011; Ahmad dan Safaria 2013; Gualo, 
Fatiya Rosyida, Sugeng Utaya, Budijanto. Pengaruh Kebiasaan Belajar dan Self-Efficacy Terhadap Hasil Belajar Geografi Di SMA

2014; Apsari, dkk. 2014; dan Williams, 2006)

Berdasarkan paparan sebelumnya dapat disimpulkan bahwa kebiasaan belajar dan self-efficacy sangat diperlukan untuk mendorong siswa dalam keberhasilan studinya. Hal tersebut memberikan konsekuensi bagi siswa untuk memiliki kebiasaan dan self-efficacy baik agar prestasi akademik yang diperoleh juga baik.Oleh karena itu, pengaruh kebiasaan dan self-efficacy terhadap hasil belajar siswa penting diteliti sebagai pertimbangan untuk menentukan strategi pembelajaran, agar hasil belajar Geografi terus meningkat. Selain itu, besarnya pengaruh kedua faktor tersebut dalam menentukan keberhasilan belajar siswa di setiap sekolah dan mata pelajaran berbeda sehingga perlu dibuktikan dengan penelitian.

\section{METODE}

Penelitian dilakukan selama dua minggu di SMAN 1 Widang-Tuban. Hal tersebut dilakukan karena menyesuaikan jadwal sekolah. Penelitian ini menggunakan pendekatan kuantitatif yang berdasarkan tingkat eksplanasinya adalah deskriptif, karena bertujuan membuat gambaran secara sistematis, faktual, dan akurat mengenai variabel bebas terhadap variabel terikat. Variabel bebas adalah kebiasaan belajar dan self-efficacy, se- dangkan variabel terikat adalah hasil belajar siswa.

Kebiasaan belajar diukur dengan Study Habit Inventory yang dikembangkan oleh Bakare tahun 1971, selfefficacy diukur dengan Motivation and Strategi Learning Quetionare (MSLQ) yang dikembangkan oleh Pintrich dkk tahun 1991, sedangkan hasil belajar siswa diperoleh dari nilai rata-rata ulangan. Teknik pengambilan sampel menggunakan cluster sampling karena kondisi populasi terdiri dari kelas X, XI, dan XII sehingga untuk menghindari satu kelas terlalu banyak yang terpilih sebagai sampel, sebaliknya kelas lain tidak terwakili dalam proses. Analisis data yang dilakukan menggunakan analisis statistik regresi.

\section{HASIL}

\section{Uji Asumsi Klasik}

Uji asumsi klasik meliputi normalitas, autokrelasi, multikolinieritas, heteroskedastisitas, dan linieritas. Uji tersebut dilakukan sebagai prasyarat sebelum dilakukan uji regresi linier ganda. Hasil uji asumsi klasik pada data penelitian menunjukkan bahwa tidak ada masalah, artinya semua uji memenuhi syarat untuk dilakukan analisis regresi. Berikut hasil uji asumsi klasik pada tabel 3.1. 
Tabel 3.1 Hasil Uji Asumsi Klasik Data Penelitian

\begin{tabular}{|c|c|c|c|}
\hline Uji Asumsi Klasik & $\begin{array}{l}\text { Uji yang } \\
\text { digunakan }\end{array}$ & Hasil & Kesimpulan \\
\hline Normalitas & $\begin{array}{l}\text { Kolmogorov- } \\
\text { Smirnov Test }\end{array}$ & $\begin{array}{l}\text { Sig kebiasaan belajar }=0,754 \\
\text { Sig self-efficacy }=0,185 \\
\text { Sig Hasil Belajar }=0,66\end{array}$ & $\overline{\text { data }}$ \\
\hline Autokorelasi & Durbin-Watson & DW hitung $=1.652$ & $\begin{array}{l}\text { tidak ada autokorelasi posi- } \\
\text { tif maupun negatif }\end{array}$ \\
\hline Multikolinieritas & $\begin{array}{l}\text { Variance Inflation } \\
\text { Factor (VIF) }\end{array}$ & $\begin{array}{l}\text { VIF kebiasaan belajar }=1,375 \\
\text { VIF self-efficacy }=1,375\end{array}$ & tidak ada multikolinieritas \\
\hline Heterokedastisitas & Uji Glejser & $\begin{array}{l}\text { Sig kebiasaan belajar }=0,707 \\
\text { Sig self-efficacy }=0,785\end{array}$ & tidak ada heteroskedastisitas \\
\hline Linieritas & Test of Linierity & $\begin{array}{l}\text { Sig Kebiasaan Belajar }=0,064 \\
\text { Sig Motivasi Belajar }=0,127\end{array}$ & $\begin{array}{l}\text { Terdapat hubungan linier var- } \\
\text { iabel X dengan variabel Y }\end{array}$ \\
\hline
\end{tabular}

\section{Uji Hipotesis}

Uji Hipotesis dilakukan dengan menggunakan regresi pada program SPSS. Dari uji tersebut, terlihat bahwa ketiga hipotesis nol ditolak, artinya terdapat pengaruh variabel bebas terhadap variabel terikat baik secara parsial maupun simultan. Selain menguji hipotesis, regresi juga menghasilkan sumbangan efektif. Sumbangan efektif kebiasaan belajar $(65,90 \%)$ lebih besar apabila dibandingkan dengan self-efficacy $(15,80 \%)$. Secara lengkap dapat dilihat pada tabel 3.2.

Tabel 3.2. Hasil Uji Hipotesis Data Penelitian

\begin{tabular}{lllll}
\hline Hipotesis & Hasil & Persamaan regresi & $\begin{array}{l}\text { Sum- } \\
\text { bangan } \\
\text { efektif }\end{array}$ & Kesimpulan \\
\hline Hipotesis 1 & Sig $=0,000$ & $\hat{\mathrm{Y}}=10,162+0,714 \mathrm{X}_{1}$ & $65.90 \%$ & $\begin{array}{l}\text { ada pengaruh kebiasaan belajar }\left(\mathrm{X}_{1}\right) \text { terhadap } \\
\text { hasil belajar }(\mathrm{Y})\end{array}$ \\
Hipotesis 2 & $\mathrm{Sig}=0,000$ & $\hat{\mathrm{Y}}=49,125+.1,504 \mathrm{X}_{2}$ & $15,80 \%$ & $\begin{array}{l}\text { ada pengaruh self-efficacy }\left(\mathrm{X}_{2}\right) \text { terhadap hasil } \\
\text { belajar }(\mathrm{Y})\end{array}$ \\
Hipotesis 3 & Sig $=0,000$ & $\begin{array}{l}\hat{\mathrm{Y}}=10,642+0.724 \mathrm{X}_{1}+65,20 \% \\
0,080 \mathrm{X}_{2}\end{array}$ & $\begin{array}{l}\text { ada pengaruh kebiasaan }\left(\mathrm{X}_{2}\right) \text { dan motivasi } \\
\text { belajar }\left(\mathrm{X}_{2}\right) \text { terhadap hasil belajar }(\mathrm{Y})\end{array}$ \\
\hline
\end{tabular}

\section{PEMBAHASAN}

\section{Pengaruh Kebiasaan Belajar terhadap Hasil Belajar Geografi}

Secara umum, kebiasaan belajar siswa SMAN 1 Widang-Tuban tergolong sedang, sehingga mereka mendapat nilai cukup 70-79 akan tetapi tidak semua siswa memperoleh nilai cukup, terdapat siswa yang mendapat nilai baik, kurang, dan kurang sekali. Begitu pula yang terjadi pada kategori kebiasaan belajar tinggi, terdapat siswa yang mendapat nilai sangat baik, baik, hingga cukup. Berdasarkan analisis data, perbedaan hasil belajar tersebut terjadi akibat perbedaan 
94

Fatiya Rosyida, Sugeng Utaya, Budijanto. Pengaruh Kebiasaan Belajar dan Self-Efficacy Terhadap Hasil Belajar Geografi Di SMA

metode belajar, membaca, dan membuat catatan. Jika ketiga indikator tersebut tinggi, maka hasil belajar akan lebih baik (Osah-edo dan Alutu, 2012; Nuthana dan Yenagi, 2009; Oluwatimilehin dan Owoyele, 2012; dan Ibrahim, 2012).

Cara belajar berkaitan dengan penggunaan metode efektif. Metode belajar efektif penting dilakukan agar kebiasaan belajar juga menjadi efektif. Bahkan belajar efektif tidak dapat diperoleh tanpa aplikasi ketrampilan dan metode belajar."Effective study cannot be acquired without the application of these skills and methods" (Osah-edo dan Alutu, 2012). Dengan demikan dapat dinyatakan bahwa setiap siswa yang berusaha belajar dalam pola dan kebiasaan sama, tetapi keberhasilan akan menampakkan perbedaan karena metode yang digunakan berbeda. Siswa dengan metode efektif akan memperoleh hasil belajar yang lebih baik. Begitu pula sebaliknya, siswa akan mendapat hasil belajar rendah ketika menggunakan metode belajar tidak efektif.

Ketidakefektivan metode belajar telah lama ditemukan oleh psikolog sebagai penyebab rendahnya hasil belajar siswa. Hal tersebut sesuai dengan pen-dapat Udeani (2012) seperti berikut.

Psychologists have long realized that many students perform poorly in their academic work not because they do not possess the mental ability to do well but because they do not know or do not use the most effective me-thods of studying.

Perolehan nilai rendah tersebut disebabkan mereka tidak tahu bagaimana menerapkan strategi yang tepat atau mereka belajar di waktu dan tempat yang kurang tepat, tidak menentukan tujuan sebelum belajar, dan tidak membaca poin-poin penting. Kondisi tersebut menyebabkan kurangya pemahaman, ketidakmampuan dalam berkonsentrasi, dan menyia-nyiakan waktu.

Selain metode belajar, perbedaan hasil belajar disebabkan oleh efektivitas dan efisiensi membaca dan membuat catatan. Hal tersebut sesuai dengan penelitian sebelumnya yang mengatakan bahwa di antara indikator dalam Study Habits Inventory, membaca dan membuat catatan memiliki pengaruh tinggi terhadap perolehan hasil belajar siswa (Nuthana dan Yenagi, 2009; Oluwatimilehin dan Owoyele, 2012; dan Ibrahim, 2012). Membaca merupakan kegiatan yang harus dilakukan oleh siswa karena dapat meningkatkan pemahaman. Selain itu, membaca sangat penting mengingat banyaknya perkembangan pengetahuan yang tidak disampaikan oleh guru kepada siswa dalam pembelajaran di kelas, sehingga perlu pengetahuan untuk memperdalam materi tersebut di luar jam pelajaran, yaitu dengan banyak membaca.

Aktivitas membaca adalah aktivitas yang paling banyak dilakukan selama belajar di sekolah. Jika belajar adalah untuk mendapatkan ilmu pengetahuan, maka membaca adalah jalan menuju ke pintu ilmu pengetahuan. Ini berarti untuk mendapatkan ilmu pengetahuan tidak ada cara lain yang harus dilakukan kecuali dengan memperbanyak membaca. Apalagi dalam kondisi beban mata pelajaran yang banyak, kemampuan membaca efektif perlu dilakukan untuk menambah wawasan, sehingga hasil belajar akan meningkat. "If students develop good reading strategies, it increases their hori- 
zon in understanding retention of things read to enhance good academic performance" (Akagah, 2011).

Membuat catatan juga penting dilakukan karena dapat dijadikan bahan untuk belajar. Catatan yang telah dibuat dapat membantu mengingat materi dan mensintesa pengetahuan baru. Kebiasaan siswa mencatat dapat membuat pengetahuan tersimpan lebih lama karena ketika mereka lupa dapat membuka kembali catatannya."Students who use proper study habits containing note taking and studying that notes, can preserve knowledge for longer time" (Ozsoy dkk., 2009). Oleh sebab itu, membuat catatan dapat meningkatkan hasil belajar. Hal tersebut didukung oleh Johnstone dan $\mathrm{Su}$ (1994) yang menyatakan bahwa siswa yang mencatat lebih ingat materi pelajaran dan pada akhirnya nilai ujian mereka lebih baik. Osah-endo dan Alutu (2012) juga memperkuat pendapat tersebut. Mereka mengatakan bahwa membuat catatan merupakan salah satu aktivitas yang diyakini dapat membantu belajar sehingga meraih keberhasilan belajar.

Hasil penelitian ini mendukung hipotesis pertama yang menyatakan bahwa terdapat pengaruh kebiasaan belajar terhadap hasil belajar geografi siswa SMAN 1 Widang-Tuban. Hasil penelitian ini juga menguatkan terhadap hasil penelitian lain yang telah dilakukan. Penelitian tersebut menghasilkan temuan bahwa terdapat pengaruh signifikan kebiasaan belajar terhadap hasil belajar (Rahyuningsih, dkk, 2012; Wahyuningsih dan Dzajari, 2013; dan Kuswanti, 2010; Udeani, 2012; Khursid, 2012; Osah-edo dan alutu, 2012; Oyedeji, 1991; dan Siagian 2013).
Apabila dilihat dari sumbangan efektifnya, hasil penelitian ini memiliki nilai yang paling besar dibandingkan dengan penelitian sebelumnya, yakni sebesar $65,90 \%$. Hal tersebut mengindikasikan bahwa variasi hasil belajar Geografi siswa SMAN 1 Widang-Tuban mampu dijelaskan oleh kebiasaan belajar sebesar 65,90\%. Angka ini tergolong besar. Hal ini juga ditegaskan lagi oleh persamaan regresi yang dihasilkan. Persamaan tersebut adalah $\hat{Y}=10,162+0,714 X_{1}$, artinya jika kebiasaan belajar siswa ditingkatkan satu satuan maka nilai hasil belajar Geografi siswa akan meningkat sebesar 0,714 . Oleh sebab itu, siswa SMAN 1 Widang-Tuban harus meningkatkan kebiasaan belajarnya agar hasil belajar geografi dapat pula meningkat.

\section{Pengaruh Self-efficacy terhadap Hasil Belajar Geografi}

Berdasarkan hasil analisis, dapat diketahui bahwa self-efficacy siswa SMAN 1 Widang-Tuban termasuk dalam kriteria sedang, sehingga mereka memperoleh nilai cukup. Mereka yang memiliki self-efficacy rendah maka nilai juga rendah. Self-efficacy atau keyakinan diri memberikan pengaruh positif terhadap prestasi akademik seseorang. "Selfefficacy was positively related to student cognitive engagement and performance" (Pintrich dan De Groot, 1990). Hal tersebut dapat terjadi karena keyakinan seseorang pada diri sendiri akan menimbulkan sifat optimis dalam mengerjakan tugas. Sekalipun mereka mengalami kesulitan, mereka akan tetap gigih berusaha untuk dapat menyelesaikan tugas yang diberikan oleh Guru. Begitu sebaliknya, siswa dengan 
Fatiya Rosyida, Sugeng Utaya, Budijanto. Pengaruh Kebiasaan Belajar dan Self-Efficacy Terhadap Hasil Belajar Geografi Di SMA

keyakinan diri rendah akan pesimis terhadap kemampuannya mengerjakan tugas dan pada akhirnya mereka tidak mampu untuk menyelesaikannya. Hal tersebut dipertegas oleh Javanmard, dkk., (2012) berikut "individuals with low self-efficacy are pessimist about their abilities; hence they avoid situations deemed beyond their abilities".

Hasil uji regresi menunjukkan bahwa terdapat pengaruh signifikan motivasi belajar terhadap hasil belajar Geografi siswa SMAN 1 Widang-Tuban. Dengan demikian, hasil penelitian ini mendukung hipotesis kedua dan hasil penelitian sebelumnya. Penelitian tersebut menghasilkan kesimpulan bahwa motivasi belajar berpengaruh signifikan terhadap hasil belajar (Mothlag, dkk. 2011; Ahmad dan Safaria 2013; Gualo, 2014; Apsari, dkk, 2014; dan Williams, 2006).

Sumbangan efektif self-efficacy $(15,80 \%)$ lebih rendah dibandingkan kebiasaan belajar. Tidak begitu besarnya sumbangan efektif variabel self-efficacy terhadap hasil belajar dapat dipahami, karena variabel ini dipengaruhi oleh lingkungan sekitarnya. Keyakinan diri dipengaruhi oleh tingkat kompetisi dalam "self-efficacy beliefs may differ between those children in competitive classrooms and those in more cooperative environments" (Pajares and Miller, 1994; Zimmerman, 1995; William 2006). Artinya seseorang yang memiliki keyakinan diri yang tinggi akn berkurang keyakinannya jika berada pada kondisi kelas yang kurang kompetitif. Hal ini terkait dengan ketertarikan siswa dalam menyelesaikan tugas. Kondisi kurang kompetitif menyebabkan tantangan yang dirasakan kurang sehingga usaha yang dilakukan juga kurang.

Selain kondisi kelas yang kurang kompetitif, kecilnya pengaruh selfefficacy karena variabel ini merupakan titik awal dari pembelajaran, tetapi tidak secara langsung mempengaruhi hasil belajar (Wolters dan Pintrich, 1998; Rotgans dan Schmidt, 2012; Pintrich dan De Groot, 1990;Bandura, 1994; dan Crede dan Kuncel, 2008). Artinya, self-efficacy hanya mendorong seseorang untuk dapat mengatur belajarnya sendiri, selanjutnya keberhasilan belajar bergantung pada keefektivan belajarnya seperti penetapan tujuan, pemantauan diri, penggunaan strategi, evaluasi diri dan reaksi diri.

\section{Pengaruh Kebiasaan Belajar dan Self- efficacy terhadap Hasil Belajar Geo- grafi}

Hipotesis ketiga berbunyi terdapat pengaruh kebiasaan belajar dan selfefficacy secara bersama-sama juga terbukti. Sumbangan efektif yang diberikan oleh kedua variabel secara bersama tergolong tinggi sebesar 65,20\%. Dengan demikian dapat dikatakan bahwa semakin tinggi kebiasaan belajar dan self-efficacy siswa maka hasil belajar juga baik. Kebiasaan belajar tinggi dengan self-efficacy tinggi akan menghasilkan hasil belajar lebih dari 80, begitu pula kebiasaan dan self-efficacy rendah akan menghasilkan hasil belajar kurang sekali $(0-58)$, sedangkan kebiasaan belajar dan selfefficacy sedang akan menghasilkan hasil belajar cukup (70- 79) . Selain membuktikan hipotesis ketiga, hasil penelitian ini menguatkan penelitian lain yang telah dilakukan. Penelitian tersebut menunjukkan bahwa terdapat pengaruh kebiasaan 
belajar dan self-efficacy terdahap hasil belajar (Sukmawati, dkk. 2013 dan Putra, dkk. 2015).

\section{KESIMPULAN}

\section{Kesimpulan}

Hasil penelitian menunjukkan bahwa

1) kebiasaan belajar secara signifikan berpengaruh terhadap hasil belajar siswa dengan sumbangan efektif sebesar 65,90\%,

2) self-efficacy secara signifikan berpengaruh terhadap hasil belajar siswa dengan sumbangan efektif sebesar $15,80 \%$,

3) kebiasaan belajar dan self-efficacy secara signifikan berpengaruh terhadap hasil belajar siswa dengan sumbangan efektif sebesar $65,20 \%$.

\section{Saran}

Berdasarkan temuan penelitian, maka saran yang diberikan adalah

1) self-efficacy dan kebiasaan belajar perlu ditingkatkan agar hasil belajar meningkat,

2) peneliti selanjutnya diharapkan melakukan penelitian yang lebih luas dengan membandingkan sekolah satu dengan lainnya sebagai konfirmasi atau perbaikan dari penelitian ini, dan

3) peneliti selanjutnya diharapkan melibatkan banyak variabel sehingga diperoleh hasil penelitian yang lebih utuh.

\section{DAFTAR RUJUKAN}

Aluja, Anton dan Angel Blanch. 2004. Socialized Personality, Scholastic Aptitudes, Study Habits, and Aca- demic Achievement: Exploring the Link. European Journal of Psychological Assessment, Vol. 20, Issue $\mathrm{x}, \quad \mathrm{pp} . \quad \mathrm{xxx}-\mathrm{xxx}, \quad$ (online), (http://web.udl.es/usuaris/e7806312 /grup/aalujaarchi/arti_aluja/pu_47.pdf) diakses 4 Desember 2013.

Andartari. 2013. Pengaruh Kemampuan Intelektual (IQ) dan Motivasi Belajar terhadap Hasil Belajar Siswa pada Mata Pelajaran Akuntansi pada SMA Labschool Rawamangun. Jurnal Pendidikan Ekonomi dan Bisnis Vol.1 NO. 1 Maret 2013 ISSN: 2302 - 2663, (online),

(www.jpeb.net/attachments/article/ 18/ANDARTARI.pdf) diakses 2 Februari 2014.

Apsari, Bekti Susilo, dkk. 2014. Pengaruh Efikasi Diri, Pemanfaatan Gaya Belajar dan Lingkungan Teman Sebaya terhadap Prestasi Belajar Akuntansi (Studi Kasus di SMK Negeri 1 Surakarta). Jupe UNS, Vol. 3, No. 1, Hal 91 s/d 102, (online), diakses 21 April 2016.

Bandura, A. (1994). Self-efficacy. In V. S. Ramachaudran (Ed.), Encyclopedia of human behavior(Vol. 4, pp. 71-81). New York: Academic Press. (Reprinted in H. Friedman [Ed.], Encyclopedia of mental he alth. San Diego: Academic Press, 1998.

Dimyati, dan Mudjiono. 2010. Belajar dan Pembelajaran. Jakarta: PT. Rineka Cipta.

Dwija, I Wayan. 2008. Hubungan antara Konsep Diri, Motivasi Berprestasi, dan Perhatian Orang Tua dengan Hasil Belajar Sosiologi pada Siswa Kelas II Sekolah Menengah Atas Unggulan di Kota Amlapura. Jurnal Pendidikan dan Pengajaran UNDIKSHA, No. 1 TH. XXXXI 
Fatiya Rosyida, Sugeng Utaya, Budijanto. Pengaruh Kebiasaan Belajar dan Self-Efficacy Terhadap Hasil Belajar Geografi Di SMA

Januari 2008 ISSN 0215 - 8250, (online),

(http://pasca.undiksha.ac.id/images /img_item/725.doc) diakses 2 Februari 2014.

Goulão, Maria de Fátima. 2014. The Relationship between Self-Efficacy and Academic Achievement in Adults' Learner. Athens Journal of Education Vol. 1, No. 3 (online), (www.atiner.gr/journals/.../2014-13-4-Goulao.pdf.) diakses 21 April 2016.

Ibrahim, Abdulrasaq . 2012. Influence of Study Habits on Academic Achievement of Students in Motor Mechanics Work, (online), (www.basearticles.com) diakses 5 Januari 2014.

Khoshnam, Amir Hossein dkk. 2013. The Relationship between Intrinsic Motivation and Happiness with Academic Achievement in High School Students. International Journal of Academic Research in Business and Social Sciences November 2013, Vol. 3, No. 11 ISSN: 22226990, (online), (http://dx.doi.org/10.6007/IJARBSS /v3-i11/342) diakses 5 Juli 2013.

Khursid, dkk. 2012. Relationship between Study Habits and Academic Achievement among Hostel Living and Day Scholars' University Students. British Journal of Humanities and Social Sciences January 2012, Vol. 3 (2), (online), (http://www.ajournal.co.uk/HSpdfs/ HSvol-

ume3(2)/HSVol.3\%20(2)\%20Articl e\%204.pdf) diakses 29 November 2012

Mendezabal, Marie Jean N. 2013. Study Habits and Attitudes: The Road to Academic Success. International Journal of Applied Research and Studies (iJARS) Volume 2, Issue 4
(April- 2013) ISSN: 2278-9480, (online)

(http://ijars.in/iJARS\%20309.pdf) diakses 4 Desember 2013.

Motlagh, dkk. 2011. The relationship between self-efficacy and academic achievement in high school students.Procedia Social and Behavioral Sciences 15 (2011), (online).www.sciencedirect.com diakses 21 April 2016.

Nuthana, P.G. dan Ganga V. Yenagi. 2009. Influence of study habits, self-concept on academic achievement of boys and girls. Karnataka J. Agric. Sci., 22 (5) (1 135-1 138) : 2009, (online), www.cabdirect.org/abstracts/20103 137117.html) diakses 1 Januari 2014.

Oluwatimilehin, J. T. B. dan Jimoh Wale Owoyele, 2012. Study Habits and Academic Achievement in Core Subjects Among Junior Secondary School Students in Ondo State, Nigeria. Bulgarian Journal of Science and Education Policy (BJSEP), Volume 6, Number 1, 2012, (online), (bjsep.org/getfile. php?id=112) diakses 2 Februari 2014.

Osa-Edoh, G.I. dan A.N.G. Alutu. 2012. A Survey of Students Study Habits in Selected Secondary Schools: Implication for Counselling. Current Research Journal of Social Sciences 4(3): 228-234, 2012 ISSN: 20413246 , (online), (www.maxwellsci.com/print/crjss/v 4-228-234.pdf) diakses 4 Desember 2013.

Oyedeji, O. A. 1991. Perseverance, Study Habits and Self Concept as Predictors of Students' Performance in Secondary School Mathematics in Nigeria, (online), (http://unilorin.edu.ng/journals/edu 
cation/ije/dec1991) diakses 29 November 2012.

Ozsoy, Gokhan. 2009. Metacognition, study habits and attitudes . European Journal of Psychological Assessment, Vol. 2, Issue 1, October, 2009, (online), (www. files.eric.ed.gov/fulltext/ED508333. pdf) dikses 23 Desember 2013.

Pajares, Frank. (1994). Self-Efficacy During Childhood and Adolescence Implications for Teachers and Parents. (online), (http://ncfy.acf.hhs.gov/sites/default /files/docs/18464-Self-Efficacy_

Dur-

ing_Childhood_and_AdolescenceImplications_for_Teachers_ and_Parents.pdf) diakses 21 April 2016

Pintrich, Paul R. dan Elisabeth V. De Groot.1990.Motivational and SelfRegulated Learning Components of Classroom Academic Performance. Journal of Educational Psychology 1990, Vol. 82, No. 1, 3340, (online), (www.stanford.edu/ self-regulation/self-regulated) diakses 13 Juni 2013.

Rahayuningsih, Sri dkk. 2013. Pengaruh Sikap dan Kebiasaan Belajar terhadap Hasil Belajar Matematika Siswa Kelas VIII SMP Kartika 1-6 padang. Ejurnal Universitas Bung Hatta Vol 1, No 1 (2013), (online), (http://ejurnal.bunghatta.ac.id/inde x.php?journal $=J F K I P \&$ page $=$ artic le \&op =viewFile \&path\%5B\%5D= 372 \&path\% $5 B \% 5 D=262$ ) diakses 5 Juli 2013.

Rana, Shabbir Ahmad dan Rukhsana Kusar. 2011. Comparison of Study Habits and Academic Performance of Pakistani British and White British Students. Pakistan Journal of Social and Clinical Psychology Vol. 9, 21-26, (online),
(www.gcu.edu.pk/FullTextJour/PJS CS/2011/4.pdf) diakses 1 Desember 2013.

Rotgans, Jerome I. dan Henk G. Schmidt. 2012. The Intricate Relationship Between Motivation and Achievement: Examining the Mediating Role of Self-Regulated Learning and AchievementRelated Classroom Behaviors. International Journal of Teaching and Learning in Higher Education 2012, Volume 24, Number 2, 197208 ISSN 1812-9129, (online), (http://www.isetl.org/ijtlhe/) diakses 13 Februari 2014.

Siagian, Roida Eva Flora. 2013. Pengaruh Minat dan Kebiasaan Belajar Siswa terhadap Prestasi Belajar Matematika. Jurnal Formatif 2(2): 122-131 ISSN: 2088-351X, (online), (http://www.unindra.ac.id/ Roida3.pdf) diakses 2 Februari 2014).

Schunk, D. H., \& Meece, J. L. (2005). Self-Efficacy Development in Adolescences. In T. Urdan \& F. Pajares (Eds.), Self-Efficacy Beliefs of Adolescents (pp. 71-96). Greenwich, CT: Information Age Publishing.

Sukmawati, Ni Pt. Feni dkk. 2013. Hubungan antara Efikasi Diri dan Kebiasaan Belajar terhadap Prestasi Belajar Siswa Kelas V SDN di Kelurahan Kaliuntu Singaraja. (online), (http://download.portal garuda.org). diakses 21 April 2016.

Suwardi, Dana Ratifi. 2012. FaktorFaktor Yang Mempengaruhi Hasil Belajar Siswa Kompetensi Dasar Ayat Jurnal Penyesuaian Mata Pelajaran Akuntansi Kelas XI IPS di SMA Negeri 1 Bae Kudus. Economic Education Analysis Journal 1 (2) (2012), (online), (http://lib.unnes.ac.id/15332/) diakses 12 Desember 2012. 
Fatiya Rosyida, Sugeng Utaya, Budijanto. Pengaruh Kebiasaan Belajar dan Self-Efficacy

Terhadap Hasil Belajar Geografi Di SMA

Udeani, Uchenna. 2012. The Relationship between Study Habits, Test Anxiety and Science Achievement. Journal of Education and Practice Vol 3, No.8, 2012 ISSN 2222-1735 (Paper) ISSN 2222-288X (Online), (online), (www.iiste.org) diakses 23 Desember 2013.

Wahyuningsih, Sri dan M.Djazari, 2013. Pengaruh Lingkungan Sekolah dan Kebiasaan Belajar Terhadap Prestasi Belajar Akuntansi Siswa Kelas XI IPS SMA Negeri 1 Srandakan. Kajian Pendidikan Akuntansi Indonesia Halaman 137 - 160 Vol 2, No 1 (2013), (online), (www.journal.uny.ac.id) diakses 1 Januari 2014.

Williams, Jane-Webb. Self-efficacy in the primary classroom: An investigation into the relationship with per- formance. Paper presented at the British Educational Research Association New Researchers/ Student Conference, University of Warwick, 6 September 2006, (online), (http://www.leeds.ac.ukleducol/doc uments/166271.htm) diakses 21 April 2016

Wiyono, Bambang Budi. 2003. Hubungan Lingkungan Belajar, Kebiasaan Belajar, dan Motivasi Belajar dengan Prestasi Belajar Siswa. Forum Penelitian Th 15 No.1, Juni 2003, hlm 26-36 ISSN 0215-8019. Malang: Lemlit UM.

Zimmerman, Barry J. 2000. Self-Efficacy: An Essential Motive to Learn, (online),

(http://www.idealibrary.com.) diakses 21 April 2016. 